Teresa

de Lauretis * / **

Universidad de California, Estados Unidos

\section{Intertextualidad: literatura y cine}

Intertextuality: literature and cinema

\author{
El hilo de la fábula \\ Universidad Nacional \\ del Litoral, Argentina \\ ISSN-e: 2362-5651 \\ Periodicidad semestral, \\ julio-diciembre, 2021 \\ vol. 19, núm. 22, e0015, \\ revistaelhilodelafabula@ \\ fhuc.unl.edu.ar \\ Recepción: 10082021 \\ Aprobación: 25102021 \\ URL: http://portal. \\ amelica.org/ameli/ \\ jatsRepo/247/2472702015/ \\ index.html \\ DOI: https://doi. \\ org/10.14409/hf.19.22. \\ e0015
}

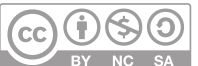

Esta obra está bajo una Licencia Creative Commons Atribución-NoComercialCompartirlgual 4.0 Internacional.

\section{Resumen}

El presente artículo trata de algunos usos de la intertextualidad entre el cine y la literatura. I Walked with a Zombie (1943) es la segunda de las nueve películas producidas por Val Lewton que dieron forma al género de terror y tuvieron una influencia duradera en el lenguaje cinematográfico. La película, que replantea la clásica novela victoriana Jane Eyre en un escenario caribeño, esboza las fallas del proceso colonizador europeo mucho antes de la llegada de los estudios postcoloniales. La novela parcialmente autobiográfica de Jean Rhys, Wide Sargasso Sea (1966), reformula Jane Eyre desde una perspectiva feminista y poscolonial por medio del punto de vista de «la loca del ático». En la novela El beso de la mujer araña (de Manuel Puig), el cine y las películas, incluida I Walked with a Zombie, constituyen el medio intertextual para la creación del personaje literario y la figura de un amor que no tiene nombre.

\section{Palabras clave}

Wal Lewton, Jacques Tourneur, Jean Rhys, Ancho mar de los Sargazos, I Walked with a Zombie, Manuel Puig, El beso de la mujer araña .

\section{Abstract}

This article is about some uses of intertextuality between cinema and literature. I Walked with a Zombie (1943) is the second of nine films produced by Val Lewton that shaped the horror genre and had a lasting influence on the language of cinema. Reframing the classic Victorian novel Jane Eyre in a Caribbean setting, the film outlines the faultlines of the European colonial enterprise long before the advent of postcolonial studies. Jean Rhys's partly autobiographical novel Wide Sargasso Sea (1966) rewrites Jane Eyre in a feminist and postcolonial perspective from the point of view of «the madwoman in the attic». In Manuel Puig's novel Kiss of the Spider Woman, cinema and films, including I Walked with a Zombie, are the intertextual means to the creation of literary character and the figure of a love that has no name.

\section{Keywords}

Wal Lewton , Jean Rhys, Wide Sargasso Sea, Manuel Puig, El beso de la mujer araña.

\footnotetext{
* Teresa de Lauretis es catedrática emérita de la Universidad de California-Santa Cruz, donde enseñó durante décadas en el Departamento de History of Consciousness. Entre otros reconocimientos recibidos a lo largo de su trayectoria, el Doctorado Honoris Causa por las Universidades de Lund (Suecia) y Córdoba (Argentina). Autora de libros que han marcado un hito en distintos ámbitos académicos y disciplinarios (semiótica, teoría del discurso, teoría feminista y de género, cine, teoría queer), sus estudios han sido traducidos a 18 idiomas. Entre ellos recordamos La sintassi del desiderio (1976), Umberto Eco (1981), Alice Doesn't (1984), Technologies of Gender (1987), The Practice ofLove (1994), Figures of Resistence (2007), Freud's Drive (2008). En la actualidad trabaja sobre las relaciones entre experiencia espectatorial, lo figural y las nociones psicoanalíticas de traducción y transferencia. ** Este artículo fue traducido por Victoria Perren (Instituto Oxford, Argentina).
} 
Es bien sabido por los estudiantes de literatura que la novela experimental de Jean Rhys, Wide Sargasso Sea (1966), reformula el clásico victoriano de Charlotte Brontë, Jane Eyre (1947), desde una perspectiva feminista y poscolonial donde se cuenta la historia desde el punto de vista de la primera esposa de Rochester, quien es una mujer loca encarcelada en su castillo. Lo que resulta menos conocido, incluso para los estudiantes de cine, es que una película de serie B bastante oscura realizada en Hollywood en 1943 replantea la historia de Jane Eyre como una película de terror ambientada en el Caribe colonial.

El cine, a diferencia de la escritura, es un arte colectivo: ningún individuo es el único responsable del resultado de un producto cinematográfico, aunque normalmente se atribuye el éxito a su director. El aparato técnico es esencial para el cine como arte, comunicación o entretenimiento porque es el medio por el cual el lenguaje del cine, su medio de expresión, se elabora a lo largo del tiempo; en ese lenguaje se basa la forma de expresión de cada película. I Walked with a Zombie es la segunda de las nueve películas que dieron forma al género de terror y que influyeron de forma duradera en el lenguaje cinematográfico gracias a sus innovaciones técnicas en materia de sonido e iluminación. ${ }^{2}$ Su singularidad se debe en parte a las circunstancias de su realización, así como al talento y la visión de su productor, Val Lewton. ${ }^{3}$

Contratado por Selznick para producir una serie de películas de serie B (películas de bajo presupuesto producidas con rapidez, con actores relativamente desconocidos, destinadas a un público numeroso y con altos resultados de taquilla), Lewton tuvo que crear historias adecuadas a los títulos asignados por el estudio cinematográfico que situaban claramente las películas dentro del popular género de terror; títulos como Cat People, I Walked with a Zombie, The Body-Snatcher, The Seventh Victim, Ghost Ship, etc. El hecho de que, a pesar de esos títulos, consiguiera producir nueve películas serias, intrigantes, bellas y con éxito económico en menos de diez años y a un costo muy bajo fue un logro por el que su nombre destaca en la historia del cine, a pesar de su temprana muerte a los 46 años. Reunió a un grupo de prometedores actores y técnicos para formar un equipo de colaboración cinematográfica en el que los actores interpretaban papeles en varias de las películas y el editor cinematográfico de una película podía ser el director de otra. ${ }^{4}$

La Unidad de Terror de Lewton, como se conocía al equipo en RKO, se dedicó con entusiasmo a la innovación y la experimentación, especialmente en el ámbito del sonido. Idearon los primeros micrófonos direccionales (donde un solo micrófono solía cubrir toda una escena) y mejoraron los sistemas de reducción de ruido, lo cual permitió la espacialización de las voces y los efectos sonoros de modo tal que las voces de las personas que aparecen en primer plano en la pantalla son escuchadas por el público como si estuvieran cerca, mientras que los sonidos de fondo, diegéticos y procedentes de lejos, se oyen como más lejanos. ${ }^{5}$

Otra innovación fue el doblaje, es decir, la regrabación de los diálogos en la postproducción, que se utilizó principalmente en el cine italiano pero que más tarde se convirtió en una práctica habitual en Hollywood.

Su experimentación sonora se vio favorecida por el género de terror, el cual se basa en el sonido para sus efectos, y de hecho había comenzado a desarrollarse con la primera oleada de películas de terror o de monstruos (por ejemplo, Frankenstein, Dracula, King Kong) en los primeros años del cine sonoro (1930-1936). Pero las películas de terror de Lewton son significativamente diferentes de sus predecesoras no solo técnicamente, en el medio de expresión, sino también en el contenido; efectivamente rediseñaron el género de terror tanto formal como temáticamente.

Desde el punto de vista formal, dotaron al lenguaje cinematográfico de una articulación más flexible de imágenes y sonido, en particular la posibilidad de desincronizarlos y desunirlos. La iluminación oscura de exteriores e interiores y el alto contraste blanco-negro de las imágenes, los cuales creaban una atmósfera de ambigüedad, premonición y amenaza invisible, influyeron en el cine mucho después de la década de 1940 y mucho más allá del género de terror, ya que fueron 
retomados en géneros convencionales como el thriller de suspenso y lo que se conoció como cine negro (Film noir). ${ }^{6}$ Sin embargo, a diferencia del suspenso, en el que el peligro que aguarda a los personajes es conocido o puede ser imaginado, el terror en las películas de Lewton se basa en la sensación de una amenaza inminente pero desconocida; ${ }^{7}$ involucra la percepción sensorial más que el intelecto, produciendo así ansiedad más que miedo.

El tema de las películas de terror de Lewton es la presencia en la vida humana de una otredad o alteridad que no es una emanación del mal o de poderes preternaturales, como en las primeras películas de terror y en muchas de las más recientes, sino que proviene de un lugar oscuro dentro del ser humano. La mujer de Cat People, que puede transformarse en una pantera bajo el influjo de las emociones sexuales, y la mujer aparentemente cataléptica de I Walked with a Zombie, que no sangra pero llora en la noche, son figuras liminares: humana y animal, viva y muerta. Sus personajes viven en una zona oscura entre el cuerpo y el alma, la sensación y el intelecto, la razón y la fe. En palabras de Martin Scorsese en el documental que produjo en homenaje a Val Lewton: «Lewton logró hablar desde un lugar de oscuridad durante épocas oscuras (la Segunda Guerra Mundial y el Holocausto) para otorgarle presencia a la pérdida y al olvido». ${ }^{8}$

Lewton supervisaba el trabajo de su equipo hasta el último detalle, editaba o revisaba todos los guiones sin ser mencionado en los créditos, y efectivamente «predirigía sus películas sobre el papel» (Scorsese, 2008). La primera de las nueve películas, Cat People (1942), se basó en realidad en uno de los cuentos de Lewton; ${ }^{9}$ al planificar la segunda película, I Walked with a Zombie, Lewton dio instrucciones a la guionista acreditada para que reuniera información sobre el vudú haitiano y la estructurara utilizando el argumento de Jane Eyre, de Charlotte Brontë. Como resultado, la película que constituye el producto final no es una adaptación de la novela como lo es el clásico Jane Eyre, protagonizado por Joan Fontaine y Orson Welles; ${ }^{10}$ I Walked with a Zombie es un sutil trabajo de intertextualidad fílmica que atestigua la notable sensibilidad histórica y transnacional de Lewton.

\section{Intertextualidad: cine y literatura}

Tal como lo anuncia su título, I Walked with a Zombie está formulada por la voz en off; la historia es contada en primera persona por una joven canadiense, Betsy Connell (Frances Dee), que acepta un trabajo como enfermera en una pequeña isla de las Indias Occidentales en el Mar Caribe cuyo nombre ficticio es San Sebastián. La narración se sitúa en un lugar exótico y lejano, pero los acontecimientos narrados tienen lugar en el presente, es decir, son contemporáneos al público que ve la película a principios de los años cuarenta. La paciente de Betsy es Jessica (Christine Gordon), quien es la esposa de Paul Holland (Tom Conway), el rico propietario de una plantación de azúcar. El nombre de la plantación es Fort Holland, lo cual indica su origen o procedencia colonial. La enfermedad de Jessica es extraña: camina y respira, pero no habla ni siente nada, como si estuviera en un estado de trance permanente. Sorprendentemente, la enfermera Betsy la oye llorar por la noche desde una alta torre adyacente a la casa familiar, pero aparentemente no se puede hacer nada para curar a Jessica. Cuando, finalmente, Betsy y Paul Holland se enamoran, no hay posibilidad de que se casen porque la esposa de Paul está físicamente viva.

La similitud de este argumento con el de la novela de Brontë, que también está narrada en primera persona por su protagonista femenina, la joven institutriz Jane Eyre, es fácilmente reconocible. Pero si las referencias intertextuales son numerosas, también hay diferencias significativas. En cuanto a la trama, el personaje que corresponde a Paul Holland es el de Edward Rochester; su esposa, el personaje que corresponde a Jessica, es una mujer loca encarcelada en el castillo de Thornfield de Rochester; nadie sabe de su existencia excepto el propio Rochester y la enfermera 
Grace Poole, que es efectivamente su guardián. También Jane Eyre, al igual que Betsy, oye gritos en la noche procedentes del ático, pero solo mucho más tarde, en un momento culminante de la novela, ella -y el lector- descubrirán quién es la misteriosa mujer del ático y por qué Jane y Rochester no pueden casarse. En la película, en cambio, Betsy y todos los habitantes de la isla saben que Jessica es la esposa de Paul Holland; además, una canción popular local, el calipso llamado «Fort Holland» (compuesto para la película y cantado en cámara por Sir Lancelot) habla de su relación amorosa con el medio hermano de Paul, Wesley Rand (James Ellison). ${ }^{11}$ El misterio de Jessica no reside en su identidad sino en la extraña naturaleza de su enfermedad, de la que se dan dos explicaciones contradictorias al principio de la película.

Paul dice: «mi mujer es una enferma mental», sugiriendo alguna forma de locura. Del mismo modo, Edward Rochester dice en la novela que se casó con su esposa en las Indias Occidentales, donde la familia de ella le ocultó el hecho de que ya estaba loca como su madre, es decir, que su locura era hereditaria y, por lo tanto, según las creencias comunes de la época, incurable. En la película, sin embargo, Wesley Rand, quien sigue enamorado de Jessica y bebe demasiado, proporciona otra explicación más impactante: insiste en que Jessica es una muerta viviente, o lo que los nativos llaman un zombi. El Dr. Maxwell (James Bell) bromea sobre Jessica, diciendo que «es una hermosa zombi», pero su diagnóstico se ajusta a la medicina occidental: explica que, debido a una fiebre tropical, partes de la médula espinal de Jessica se quemaron y por eso no tiene sentimientos ni sensaciones en su cuerpo. Esta es la versión oficial dada al principio a Betsy -y a los espectadores- por el médico y por la madre de Paul y Wesley, la señora Rand (Edith Barrett), aunque más tarde la señora Rand afirmará la creencia de Wesley de que Jessica es una zombi.

¿Qué es un zombi? En las películas de los años 30 y 40, el zombi es una figura del vudú haitiano y la religión caribeña centrada en Haití: un zombi es un cadáver reanimado, una persona que murió pero que fue devuelta por los espíritus del vudú a una especie de muerte en vida para realizar servicios y tareas a las órdenes del sacerdote vudú. El personaje de Carrefour (Darby Jones), que se sitúa en la encrucijada para proteger la entrada del templo vudú, es la representación clásica del zombi en las películas de esta época. (Su nombre, Carrefour, significa «encrucijada» en francés, ya que el francés es la lengua de base del dialecto haitiano.)

Creyendo que Paul sigue enamorado de su mujer, Betsy decide hacer lo que sea necesario para devolverle la vida a Jessica y que regrese con él. En primer lugar, Betsy y el médico convencen a Paul para que les permita probar un peligroso tratamiento médico, un shock insulínico, que no tiene ningún efecto sobre Jessica. Luego, cuando la criada nativa Alma (Teresa Harris) le habla de los «mejores médicos» del Hounfort, es decir, los curanderos/sacerdotes vudú del templo, Betsy lleva a Jessica al templo durante una ceremonia vudú. El Hounfort (o fuerte Houn, morada de los houn, los espíritus vudúes) es el «hogar» de los nativos, a diferencia de Fort Holland, que pertenece a los colonos blancos. Con la ayuda de Alma, las dos mujeres atraviesan una jungla de caña de azúcar, animales muertos colgados, cráneos humanos y otras señales de advertencia que dan miedo hasta que llegan al cruce que lleva al templo, donde Carrefour monta guardia. Se les permite pasar mostrando los parches de vudú proporcionados por Alma y llegan al lugar de culto donde los nativos cantan y bailan al son de los tambores para luego caer en trance. Durante esta larga y culminante secuencia, el líder de la ceremonia (el houngan) hiere a Jessica ritualmente con su sable, pero Jessica no sangra. Esto les confirma a los nativos que ella es un zombi: les pertenece y la quieren recuperar.

Por el momento, les permiten a las dos mujeres blancas regresar a Fort Holland gracias a la autoridad de la señora Rand, que resulta ser la curandera/sacerdotisa vudú, pero Carrefour será enviado a buscar a Jessica más tarde. El houngan hace un muñeco vudú para Jessica, que se ve así obligada a responder a la llamada vudú. Betsy y Paul intentan detenerla cerrando la puerta, pero pronto Jessica vuelve a situarse junto a la puerta cerrada. Esta vez interviene Wesley. Cree que Jessica está muerta, aunque sea una muerta viviente, y quiere que esté en paz, es decir, completamente muerta. Le abre la puerta y, antes de que Carrefour pueda alcanzarla, la apuñala en el 
corazón con una de las flechas clavadas en la estatua del viejo San Sebastián que está a la entrada de Fort Holland. La estatua de madera, como explica Paul a Betsy al principio de la película, era el mascarón de proa del barco que traía a los esclavos a Fort Holland.

Esta es una aseada solución narrativa para encajar en la línea de la historia de Jane Eyre, ya que hace posible el matrimonio de Paul y Betsy. Sin embargo, cuando se piensa en ello, esta resolución de la trama es demasiado limpia, o más bien, desigual: por un lado, se asemeja a la forma tradicional de matar a un vampiro y, por lo tanto, está en consonancia con el género de las películas de terror; pero, por otro lado, el zombi no es un vampiro. ¿Cómo pudo Lewton permitir una conclusión tan inconclusa de la película? En primer lugar, esta ya no es la historia de Jane Eyre, y el final de la película marca precisamente una de sus principales divergencias con la novela, ya que Betsy y Paul quedan al margen. En segundo lugar, la insistente presencia en la película de la estatua de San Sebastián sugiere que el final es simbólico: la forma de morir de Jessica pretende recordar al espectador el barco de esclavos y todas las personas que murieron en él durante la trata transatlántica de esclavos. De hecho, la figura del zombi remite inicialmente a esa historia.

\section{Intertextualidad: cine y cine}

Al tratarse de una película de terror, la presencia de zombis no es sorprendente hoy en día, pero quien esté familiarizado solo con los zombis de las películas de terror recientes puede llegar a sorprenderse. Los zombis modernos son una versión totalmente nueva del zombi clásico. Empezando por la saga de George Romero, desde Night of the Living Dead (1968), Dawn of the Dead, etc., hasta Survival of the Dead de 2009 y más allá, los zombis son figuras de un imaginario totalmente diferente, el cual predomina en la cultura popular contemporánea. El etnógrafo argentino Gustavo Blázquez señala que

los zombis actuales de series como la norteamericana Walking Dead y la británica Dead Set y los poszombis de In the Flesh, producida por la BBC, son herederos de esa tradición [de Romero]. Las relaciones con la magia, el vudú, Haití, el Caribe y los esclavos africanos desaparecieron. Ya no se trata de sujetos que perdieron su voluntad, sino de muertos que, por alguna razón, vuelven masivamente a la vida y atacan a los vivos. Las hordas de zombis no están bajo control de empresarios capitalistas (como lo estaban los esclavos de las plantaciones). Ahora son autómatas de destrucción, consumo voraz y encarnizado de carne humana, más específicamente, cerebros. ${ }^{12}$

La figura clásica del zombi, que se popularizó tras la película de terror de Lewton y en parte debido a su éxito, era una representación indirecta y típicamente racista de las personas africanas esclavizadas y llevadas a trabajar a los territorios coloniales de España, Portugal, Inglaterra, Francia y los Países Bajos en el continente americano, especialmente el Caribe. La trata transatlántica de esclavos y la institución legal de la esclavitud relacionada con ella duraron nada menos que cuatro siglos, desde finales del siglo XV hasta finales del siglo XIX.

Antes de I Walked with a Zombie, el personaje solo había aparecido en la película White Zombie, dirigida por Victor Halperin y producida independientemente por su hermano Edward en $1932 .{ }^{13}$ La película de Lewton se refiere a ella directamente o, mejor dicho, intertextualmente. Con esto quiero decir que un texto (cualquier texto, una novela, un poema, una obra de teatro o una película) que refiere o alude a otras obras intencionadamente, de forma más o menos explícita, pretende resonar con esos artefactos culturales o artísticos e invitar a la comparación y a la reflexión crítica; dicha reflexión puede ser histórica, estética, política, o todas ellas.

White Zombie también está ambientada en una isla del Caribe, implícitamente Haití. Comienza con dos jóvenes estadounidenses blancos, un empleado bancario y su prometida Madeleine, que 
son llevados en carruaje a la casa del Sr. Beaumont, un colono francés blanco, que había conocido a la pareja en el barco y los había invitado a celebrar su boda en su mansión. De camino a la mansión, el carruaje con los recién llegados se detiene porque un grupo de nativos negros con tambores y cantos rituales están en proceso de enterrar un cadáver en medio de la carretera. El cochero negro les informa escuetamente que los muertos son inhumados y se les hace trabajar por la noche en los ingenios azucareros. Entonces el cochero divisa a un grupo de extraños personajes que caminan rígidamente detrás de un hombre de aspecto diabólico (interpretado por Bela Lugosi) que se detiene ante el carruaje, mira ferozmente a la chica y le roba el pañuelo. El cochero, aterrorizado, solo acierta a decir: «Cadáveres. Zombis. Muertos vivientes» y prosigue con la marcha. Esta es la escena referida, o «citada», en la película de Lewton, con importantes diferencias a las cuales me referiré más adelante.

El personaje de Bela Lugosi es un maestro vudú blanco llamado Murder Legendre. ${ }^{14}$ Es el dueño del ingenio azucarero, así como el hombre más rico de la isla. Mediante sus poderes mágicos y pociones, toma el control de la voluntad de las personas y las convierte en zombis, vengándose así de sus enemigos y apoderándose de todo lo que desea. Los raros hombres que caminan detrás de él son su guardia personal de zombis, los hombres blancos que solían ser sus antiguos enemigos. En este caso, lo que Legendre codicia es la chica Madeleine. Le roba el pañuelo para hacerle un muñeco vudú, atraerla a su castillo y apoderarse de ella; una vez convertida en zombi, se convierte en su esclava sexual. El título White Zombie se refiere claramente a ella, pero su forma singular sugiere además una excepción, ya que los zombis que vemos trabajando como esclavos en el ingenio azucarero son todos hombres africanos. Dicho de otro modo, si la película trata de un solo zombi blanco, los hombres blancos de la guardia del cuerpo de Legendre no cuentan como zombis y la excepción es Madeleine, o más bien su condición de esclava sexual.

Al sexualizar la figura del zombi, el título de la película pretende sensacionalizar a la mujer blanca como objeto sexual. Sin embargo, al ver la película hoy en día, cualquier persona con un mínimo conocimiento de los hechos históricos observará la ironía involuntaria del título de la película, en la medida en que Madeleine, una mujer blanca convertida en una esclava sexual, ocupa la posición de las mujeres negras esclavas que fueron utilizadas sexualmente por sus propietarios blancos. Como los hijos nacidos de esas uniones, bajo la institución de la esclavitud, también eran esclavos, tanto los hombres como las mujeres esclavas aumentaban la riqueza de sus propietarios blancos. La película, por supuesto, se detiene mucho antes de sugerir esto. Al final, cuando Legendre es asesinado, la vida de Madeleine se restablece instantáneamente y la película prosigue con el habitual final feliz.

A diferencia de White Zombie, la película de Val Lewton hace referencia directa a la trata de esclavos y lo hace precisamente en la secuencia que «cita» la película anterior. La secuencia es la llegada de Betsy en una diligencia a la casa de su patrón en San Sebastián. Aunque la «llegada en carruaje» se había convertido en un tópico del cine de terror desde el primer Drácula, la similitud de la secuencia del carruaje en White Zombie y en I Walked with a Zombie señala a esta última como una cita intertextual. En la primera película, el cochero negro solo expresa su terror a los zombis transmitiéndolo a los espectadores y preanunciando el horror que se avecina. En la segunda, el viejo cochero negro le cuenta tranquilamente a la recién llegada Betsy la historia del lugar, un lugar todavía marcado por el horror del tráfico de esclavos. «Fort Holland era un fuerte que ya no existe» dice; la familia Holland, propietaria de la empresa azucarera, es la más antigua de la isla; «ellos trajeron a la gente de color en Ti -Misery... el enorme barco trajo a los padres y a las madres de todos nosotros, encadenados al fondo del barco». ${ }^{15}$

El viejo cochero se refiere explícitamente a lo que la historia conoce como «El Pasaje del Medio», uno de los aspectos más espantosos del comercio transatlántico de esclavos. La respuesta de la mujer blanca canadiense, que evidentemente no sabe nada de ello, es: «les trajeron a un lugar hermoso». El cochero negro, que claramente sabe que no debe llevar la contraria a una persona blanca, no se inmuta y solo responde: «Si usted lo dice, señorita, si usted lo dice...» Llegados a 
este punto, a los espectadores de la película se les puede ocurrir que el nombre de la plantación, Fort Holland, al igual que el de su propietario, Paul Holland, no fueron elegidos al azar sino que constituyen una referencia directa al comercio transatlántico de esclavos y al papel de los barcos holandeses en el transporte de los esclavos, la carga humana, a las Américas y en el posterior transporte a Europa del cargamento de mercancías que incluían azúcar, café, cacao, especias, maderas preciosas, artefactos nativos, etc. El propio Paul Holland le cuenta a Betsy que la estatua del negro San Sebastián, el cual da nombre a la isla, había sido el mascarón de proa de ese barco negrero. Lo vemos de pie a la entrada de Fort Holland como si mantuviera vivo el recuerdo de esa historia y vigilara sus reverberaciones actuales.

Porque no todo va bien en Fort Holland. Cuando Paul y la joven enfermera se encuentran en el barco que la lleva a la isla, Betsy queda seducida por el canto lastimero de los marineros y la belleza exótica del lugar, pero Paul solo ve muerte y decadencia: «No es bello... esos peces voladores saltan aterrorizados porque peces más grandes quieren devorarlos... aquí no hay belleza, solo muerte y decadencia... todo muere aquí, incluso las estrellas». Y, en efecto, su esposa ha enfermado de forma incurable; él y su medio hermano están distanciados por la relación adúltera de Wesley con Jessica y la negativa de Paul a dejarla marcharse con él; su madre, que tras la muerte del padre de Paul se había vuelto a casar con el misionero Dr. Rand, ha seguido trabajando en el dispensario para llevar ayuda médica a los nativos, al principio consintiendo su credibilidad en el vudú y luego adoptándolo plenamente.

Quizás el elemento más significativo introducido por Val Lewton en la narración de Jane Eyre sea la presencia real de una cultura no occidental, sus creencias y formas de supervivencia, en el contexto de la narración de la familia colonial blanca. El conflicto que la cultura no occidental introduce en la herencia occidental se focaliza en la condición de Jessica y en el personaje de la señora Rand. Curandera de profesión, la Sra. Rand se encuentra atrapada entre los conocimientos médicos occidentales y las prácticas a veces más eficaces del vudú. Les confiesa a los miembros de su familia que ella es la culpable del estado de Jessica: al ver a su familia destruida por el conflicto entre sus dos hijos, la Sra. Rand, como practicante de vudú, cayó poseída por los espíritus vudú y les pidió que convirtieran a Jessica en un zombi. El médico occidental se opone al fundamento del propio vudú. Sostiene que, aunque Jessica estaba en coma, no murió y, por tanto, no puede ser un zombi.

La película no toma partido ni por la fe haitiana en el vudú, que los holandeses califican de «superstición», ni por los conocimientos médicos occidentales que son incapaces de arrojar luz sobre el estado de Jessica. Aunque se la muestra como obligada a responder a la llamada del vudú, Wesley la mata antes de que se pueda resolver la cuestión «objetiva» de si es o no un zombi. La película trata con tacto la zona oscura entre la razón y la fe, el territorio desconocido de la muerte, o para decirlo como Hamlet: «el país del que ningún viajero regresa». Al final, Wesley y Jessica se ahogarán y sus cuerpos serán rescatados por los nativos, que ya no son esclavos, aunque siguen siendo totalmente pobres y continúan con sus propias formas de vida sin tener en cuenta a los blancos.

Lo que muestra esta película de terror es la decadencia de la empresa colonial occidental. Las palabras de Paul al principio de la película: «aquí no hay belleza, solo muerte y decadencia... aquí todo muere, incluso las estrellas» no solo se refieren al fracaso del colonialismo, sino a lo que este ha dejado en las tierras que ocupó, para los nativos que viven en ellas y para al menos una familia colonial, los Holland. ${ }^{16}$ En síntesis, al recibir del Estudio cinematográfico la tarea de producir una película con un título tan poco prometedor como I Walked with a Zombie, Val Lewton logró introducir lo que puede llamarse una perspectiva protofeminista y protodescolonial en un género de entretenimiento popular mucho antes de que los estudios feministas y descoloniales formaran parte del discurso académico, intelectual y político.

Históricamente, la ambientación de Jane Eyre de Brontë a principios y mediados del siglo XIX coincide con el punto álgido del colonialismo británico. Según la novela, Rochester se casó con su rica y loca esposa en Jamaica, la cual era una posesión británica en las Indias Occidentales. A mediados del siglo XX, cuando se desarrolla la película de Val Lewton, Fort Holland y la familia 
Holland están en decadencia; el colonialismo ha dejado de ser una forma aventurera para que los europeos adquieran riqueza y una alta posición social. En 1966, unos 20 años después de que se produjera I Walked with a Zombie y probablemente sin conocer la película, la novela parcialmente autobiográfica de Jean Rhys, Wide Sargasso Sea, proporciona un rico trasfondo sociopolítico a la visión de las Indias Occidentales coloniales que la película de Lewton bosqueja brillantemente. Tanto Lewton como Rhys, independientemente el uno del otro, reconciben a Bertha Mason como una víctima o daño colateral del colonialismo.

\section{Intertextualidad: literatura y literatura}

Jean Rhys (1890-1979) fue una criolla blanca nacida en la isla caribeña de Dominica, situada geográficamente entre los territorios franceses de Guadalupe y Martinica, cuando Dominica era todavía una colonia británica. ${ }^{17}$ Vivió allí hasta los 16 años, cuando fue enviada a la escuela en Inglaterra, y nunca regresó a las Antillas más que en el recuerdo, un recuerdo que debió intensificarse con el proceso de escritura y que cobra dolorosa vida en su última novela.

Wide Sargasso Sea es la historia de Bertha Mason, un personaje ficticio de la novela Jane Eyre. Es la mujer misteriosa de cuya identidad el lector es finalmente informado, en la última parte de la novela, por el propio Rochester: él se había casado con Bertha Mason por dinero en las Indias Occidentales sin saber de su locura, la trajo de regreso a Inglaterra y la mantuvo encarcelada en el ático de su castillo. Aunque este personaje es crucial, incluso fundamental para la narración, ya que es el impedimento para que Rochester se case con Jane y quien finalmente incendia el castillo y provoca la ceguera de Rochester, Brontë deja ese personaje misterioso sin desarrollar, muy probablemente para añadir el elemento de suspenso predilecto del género de la novela gótica en aquella época. Wide Sargasso Sea no solo contiene referencias intertextuales precisas a Jane Eyre, como los nombres de los personajes, sino que reescribe explícitamente la parte de la novela de Brontë que se refiere a la primera esposa de Rochester, rellenando las lagunas temporales. En otras palabras, Rhys vuelve a contar la historia que Rochester le cuenta a Jane en Jane Eyre, pero esta vez desde el punto de vista de la propia «loca del ático». ${ }^{18}$ Para empezar, no se llama Bertha Mason sino Antoinette Cosway.

El estilo de narración de Wide Sargasso Sea es tan distinto del de la novela victoriana como sus personajes, presentados en su propia voz o en la de otros personajes, su abundancia de discurso indirecto libre, su temporalidad no lineal y su ambientación en Jamaica y Dominica en lo que entendemos debe ser la década de 1830. La primera parte, escrita -o mejor, hablada- en primera persona por Antoinette, describe su vida de joven criolla, sola con una madre distraída y emocionalmente inestable en una mansión colonial en ruinas hasta su matrimonio concertado con Rochester. La historia de su familia, que está plagada de desastres y que se puede leer a lo largo del libro a través de las voces de Antoinette, los sirvientes de la casa y los siempre presentes e invasivos cotilleos de la isla, presagia su propia historia y, en cierto modo, la determina.

Su madre Annette, una criolla blanca de la Martinica francesa mucho más joven que su marido, el señor Cosway, quedó como heredera tras la muerte de este por alcoholismo cuando la finca ya estaba en decadencia. Después de que la Ley de Emancipación británica liberara oficialmente a los esclavos en 1833, los propietarios de las plantaciones coloniales, sin mano de obra esclava para trabajar sus tierras, fueron perdiendo poco a poco toda su riqueza y sus posesiones. Durante una conversación con un vecino (que poco después se suicida), Antoinette escucha a su madre decir que «todavía están esperando la indemnización que los ingleses les prometieron cuando se aprobó la Ley de Emancipación». ${ }^{19}$ Incapaz de administrar sola su hacienda y de soportar su soledad, Annette se casó con un colono británico de más edad, el Sr. Mason, que se convirtió así en el padrastro de Antoinette. Como las mujeres, según la ley británica, no podían conservar su herencia cuando se 
casaban, el patrimonio de Annette pasó directamente al Sr. Mason, quien le brindó una gran dote a Antoinette que incluía la mansión en la que creció y siguió viviendo hasta que un inexplicable incendio la destruyó. Su matrimonio no prosperó; el comportamiento irracional de Annette tras la muerte de su joven hijo Pierre en el incendio hizo que su segundo marido la trasladara a una casa más pequeña para que fuera atendida por una pareja de criados. Una vez, al visitar a su madre, Antoinette presenció con impotente furia cómo la emborrachaban y abusaban sexualmente de ella. Más tarde le dijeron que su madre había muerto, nunca recuperándose de su locura.

Lo que aparece como «locura» en la madre de Antoinette y más tarde en la misma Antoinette es la manifestación de su desamparo y desesperación, el resultado de la pobreza, el alcoholismo, el aislamiento total y la privación cultural más absoluta. Los negros y mestizos, antiguos esclavos o hijos de antiguos esclavos para los que ser sirvientes es la única forma de ganarse la vida, los odian o, en el mejor de los casos, los desprecian, les roban lo que pueden y se refieren a ellos más o menos abiertamente como «cucarachas blancas». ${ }^{20}$ Su odio se manifiesta siempre que es posible, como en el incendio anónimo de la casa de la familia Cosway y, anteriormente, en el envenenamiento del caballo de Annette, que era su único medio para salir de la finca aislada y llegar a la ciudad. El racismo y el sentimiento de superioridad de los blancos, al igual que los valores sexistas de la cultura colonial blanca, son evidentes en Rochester y en los blancos que hacen negocios en las islas, que también desprecian a las herederas criollas por ser mujeres sin esposo, pobres y poco dispuestas a abandonar el estilo de vida con el que se habían criado.

Tras la muerte del Sr. Mason, su hijo Richard se hizo cargo de toda la propiedad, incluida la dote de Antoinette. Queriendo deshacerse de la joven, ahora completamente sola en la ruinosa finca familiar y sin ninguna guía, salvo una fiel sirvienta negra, Richard Mason arregló su matrimonio con Rochester y le ofreció su dote (este es el «hermano» que visita a Bertha Mason en Jane Eyre). La propia voz de Rochester en primera persona y su libre discurso indirecto acabarán por confirmar su historia tal y como se cuenta en la novela de Brontë: siendo el segundo hijo y sin poder heredar nada de su patrimonio familiar, acepta un matrimonio que le haría ganar riqueza y, esperaba, el amor y la estima de su padre. Viaja a Spanish Town, Jamaica, donde se cierra el trato y se celebra la boda, aunque no sin dudas y vacilaciones por ambas partes.

La segunda parte de Wide Sargasso Sea tiene lugar durante su «luna de miel» y mientras viven juntos en las Indias Occidentales en una casa más pequeña que pertenecía a la madre de Antoinette. Está escrita principalmente en la voz de Rochester en primera persona, con dos breves secciones en la voz de Antoinette en primera persona. Esta es la forma estilísticamente más atrevida y eficaz de Rhys para transmitir la imposibilidad de diálogo entre dos jóvenes que no se entienden ni se entenderán nunca. Su educación, sus valores culturales, sus experiencias vitales y sus expectativas de género son incompatibles; su relación está marcada por la desconfianza mutua, la decepción sexual y la traición afectiva. A él le seduce la belleza exótica de Antoinette y la naturaleza exuberante que les rodea, pero al mismo tiempo le molesta el brillo del sol, el ataque constante de polillas, escarabajos e insectos diversos, la familiaridad de los sirvientes negros y su incomprensión de los hábitos de sueño, las risas repentinas y los miedos indefinibles de Antoinette. Ella se siente insegura de sí misma y teme volverse loca como su madre, pero no puede decírselo a Rochester y solo habla de morir. Antoinette ama las flores y los colores de su isla; piensa en Inglaterra como un lugar oscuro y sin color donde la gente es severa y antipática.

Cuando intentan entablar conversación, pronto empiezan a pelearse; ella se vuelve loca de ira y él recurre a la bebida. Cuando ella cierra la puerta con llave, él se acuesta con una joven sirvienta en la habitación contigua, luego le paga y la despide. La necesidad de amor y afecto de Antoinette es respondida con el frío razonamiento de Rochester de que la desea, pero no la ama. Antoinette descubre que su medio hermano prácticamente la ha vendido a Rochester y se da cuenta de que está totalmente ligada a él; habiendo perdido incluso su libertad, comienza a odiarlo. Rochester recibe una carta de un hijo ilegítimo del padre de Antoinette, o eso dice la carta, que intenta chantajearle con información maligna sobre la familia Cosway: el padre, un borracho que mantiene 
relaciones sexuales con esclavas negras y luego las desecha a ellas y a sus hijos como si fueran ropa usada; Annette y Antoinette, volubles y sexualmente promiscuas; todos, hombres y mujeres, condenados a la locura hereditaria. Rochester despide al mestizo sin ceder al chantaje, pero la duda se apodera de él y se exacerba. Su odio hacia el país se concentra aún más en Antoinette: comienza a llamarla Bertha, uno de los nombres de su loca madre, para resolver su ambivalencia y convertir en odio la atracción-repulsión que siente hacia ella y hacia las Indias Occidentales. Al final decide regresar a Inglaterra con la esposa loca que ahora odia definitivamente.

La tercera parte de Wide Sargasso Sea está narrada íntegramente por Antoinette, ahora encarcelada en el castillo de Rochester en Inglaterra, salvo un breve prefacio realizado por Grace Poole. Antoinette, incapaz de discernir la realidad de la fantasía, no reconoce a Richard Mason cuando viene a verla y ni siquiera recuerda que lo atacó con un cuchillo. Sueña que se apodera de las llaves cuando Grace Poole está borracha y dormida, que sale del ático, recorre el castillo incendiando la alfombra y las cortinas hasta llegar a las almenas, siguiendo la novela de Brontë como guión. Pero cuando, al mirar hacia abajo, Antoinette ve la piscina de la casa de su infancia en Jamaica, grita y salta, y se despierta. La señora Poole también se despierta con el grito, pero, al no ver nada raro en la habitación del ático que comparte con «Bertha», vuelve a dormirse. Entonces Antoinette se levanta y dice: «Ahora por fin sé por qué me han traído aquí y lo que tengo que hacer» (190). La novela termina con ella saliendo de nuevo del ático, a punto de incendiar el castillo.

El sueño de incendiar el castillo, el cual demuestra a Antoinette la forma de actuar, es un sueño de libertad, aunque la libertad reside en la muerte. Este final resuena misteriosamente con el de otra novela de aproximadamente la misma época y con un estilo de narración igualmente radical, una novela que, además, hace un uso muy interesante de la intertextualidad, pero esta vez con el cine.

\section{Intertextualidad: literatura y cine}

El beso de la mujer araña (1976), de Manuel Puig, está escrita casi en su totalidad con las voces en primera persona y el discurso indirecto libre de los dos protagonistas: Valentín Arregui, un joven preso político marxista bajo uno de los regímenes reaccionarios de Argentina, y Luis Alberto Molina, un decorador de escaparates transgénero quien se considera mujer, que fue encarcelado por «corrupción de menores» (23). Están confinados en el espacio restringido de una única celda de la cárcel en el Buenos Aires de 1975. Dos secciones muy breves de la novela están escritas en el lenguaje impersonal de la burocracia carcelaria. La primera, a mitad del libro, informa al lector que Molina fue trasladado a la celda de Arregui. A esto le sigue una conversación en la que el alcaide le ofrece a Molina un indulto a cambio de información sobre las actividades políticas de Arregui, y Molina finge estar de acuerdo para obtener paquetes de comida especiales que presumiblemente provienen de su madre. Hacia el final del libro, tras haber fracasado intencionadamente en su papel de informador policial, Molina es puesto en libertad condicional. La segunda sección impersonal es un informe oficial de vigilancia de la policía en el que se enumeran todas las actividades de Molina después de su puesta en libertad y en el que se indica además que, dos semanas después, en el proceso de ser detenido tras una llamada telefónica sospechosa, fue asesinado por disparos provenientes de un vehículo extremista que pasaba por allí.

Una relación amorosa entre los presos parece tan improbable como la de Antoinette y Rochester. El modo en que se dirigen el uno al otro es significativo: Molina se dirige a Valentín por su nombre de pila, mientras que Valentín se dirige siempre a Molina por su apellido (cuya terminación es femenina en español). En el transcurso de su estancia en la cárcel, Molina se enamorará 
de Valentín, pero este es un confirmado macho heterosexual enamorado de Marta, la mujer burguesa a la que abandonó para perseguir sus ideales revolucionarios. Sin embargo, una especie de amor crece lentamente en Valentín en contra de su voluntad, ya que Molina se ocupa diariamente de su comodidad y hace pasar las largas horas de prisión contándole películas de memoria.

En El beso de la mujer araña, la intertextualidad forma parte de la propia novela: sus personajes toman forma al hablar de cada película, ya que sus personalidades y deseos se revelan en sus respectivas identificaciones y desidentificaciones con los personajes y escenarios de las películas. Las películas, tan importantes como la comida sana, los dulces y los artículos de confort general, incluida el agua, que Molina le proporciona a Valentín en el horror cotidiano de su vida en la cárcel, establecen un vínculo entre ellos que les unirá en el sueño de libertad con el que termina la novela.

La novela de Puig se abre con la narración de Molina, casi plano a plano, de Cat People (la película de Val Lewton), en la que los detalles visuales y sonoros, asombrosamente precisos, superan algunos cambios menores en la ambientación debidos, ciertamente, a las preferencias personales de Molina en cuanto a moda y decoración de interiores. I Walked with a Zombie es la cuarta película que narra Molina, con varios lapsos de memoria por haber visto la película muchos años antes. También aquí la película está contada con acertados detalles visuales y sonoros -la figura del zombi negro Carrefour, una sombra que pasa por la ventana de la enfermera Betsy, la música calipso, el ritmo de los tambores en el Hounfort, el muñeco vudú atravesado por el sable-, pero mucha confusión en la trama y los personajes. Evidentemente, para compensar los lapsos de memoria, Molina inserta más fantasías propias y convierte la película en un romance, con su escenario sentimental favorito de un matrimonio tradicional y un final feliz. ${ }^{21}$

También es posible imaginar que la memoria de Molina de esta película está infiltrada por los recuerdos de la película White Zombie, que Puig podría haber visto o conocido. Pero esto sería leer la novela como realismo, que es precisamente la trampa que Puig tiende al lector mediante los diálogos, los coloquialismos y las actividades cotidianas y mundanas que componen la novela. El sentido de la novela, por el contrario, es la construcción de dos personajes y una relación entre ellos que es un tipo de amor al que los términos «homosexual» y «heterosexual» son igualmente inaplicables. La narración de Molina revela su propia personalidad, sus expectativas de género femenino nunca cumplidas en el mundo real, y su fuga creativa de la realidad hacia el cine para dar presencia a sus fantasías de belleza, riqueza, éxito, admiración y amor romántico, que Valentín constantemente menosprecia e intenta desacreditar. ${ }^{22}$ El personaje de Valentín también se construye con sus palabras, y aún más con sus silencios, es decir, con su reticencia a revelar sus pensamientos internos a su compañero de celda. Su rabia hacia sus padres de clase alta, su vergüenza por aprovecharse sexualmente de una joven india, su sentimiento de culpa por sus acciones violentas en la guerrilla, ya sean reales o fantaseadas, se expresan en largos monólogos internos y secciones de flujo de conciencia que parecen impulsadas por las películas contadas por Molina. Los cambios que se producen en Valentín a través de su interacción, que se hacen evidentes lentamente en los diálogos, se expresan plenamente en el sueño que concluye la novela tras la muerte de Molina.

Valentín, quien agoniza tras la tortura, recibe morfina de un amable enfermero. El sueño lo lleva fuera del hospital a un lugar oscuro donde se pregunta cómo puede seguir caminando, agotado como está, y una voz le dice que no tenga miedo porque el amable enfermero le ayudará. Responde a la voz, que es Marta hablando dentro de él. No puede abrir los ojos porque está dormido, dice, pero le cuenta a Marta que lo llevan por un largo túnel hasta donde puede tocar el agua y finalmente llega al mar, y luego a una isla donde puede tumbarse en la arena calentada por el sol.... A lo largo del sueño Valentín continúa el diálogo con «Marta»: «No sabés qué linda es esta mezcla de palmas, de lianas, a la noche está todo plateado, porque la película es en blanco y negro». Le habla de la mujer araña: «pobrecita... no puede moverse, ahí en lo más espeso de la selva está atrapada en una tela de araña, o no, la tela de araña le crece del cuerpo de ella misma... Le pregunto por qué es que llora y en un primer plano que ocupa toda la pantalla al final de la película ella me contesta que eso es lo que no sabe, porque es un final enigmático...» (285). 
A medida que avanza el sueño, las respuestas de «Marta» suenan cada vez más como si fueran pronunciadas por Molina, utilizando las mismas frases y oraciones que la voz de Molina había pronunciado en la celda de la prisión. El último intercambio no deja lugar a dudas:

«eso es lo único que no quiero saber, el nombre de tus compañeros», ¡Marta, ay cuánto te quiero; eso era lo único que no te podía decir, yo tenía miedo de que me lo preguntaras y de ese modo sí te iba a perder para siempre, «no, mi Valentín querido, eso no sucederá, porque este sueño es corto pero es feliz» (286-287)

La afirmación de Valentín, en cursiva, es al principio tan enigmática como el final de la película en el que «la mujer araña llora en un primer plano que ocupa toda la pantalla». Pero Valentín es un intelectual que siempre busca explicaciones y claridad. En consonancia con su carácter, pues, la afirmación puede entenderse así: si Molina le hubiera preguntado: «iMe querés?», Valentín no podría haber respondido «sí» porque no podría amar a Molina como Molina esperaría, es decir, como un hombre que ama a una mujer. Su amor por Molina no es heterosexual, como el que sentía por Marta, pero tampoco es homosexual, término que no se aplica a Molina y que esta rechazaría por sentirse mujer. Así que el de Valentín no es «el amor que no se atreve a decir su nombre», sino un amor que no puede decir su nombre porque no hay nombre para él. ${ }^{23}$ Por supuesto, si hubiera respondido «no», habría sido una mentira y habría perdido a Molina para siempre. El logro de la novela es la verdad de ese amor innombrable.

Cuando este sueño es filmado por Héctor Babenco en El beso de la mujer araña (1985), la novela de Puig queda menospreciada. La presencia en pantalla de la actriz Sonia Braga hace que sea muy improbable escuchar las últimas palabras de Valentín dirigidas a Molina, como claramente son en la novela. Debido a que el lenguaje del cine es audiovisual, hecho de imágenes y sonidos, y las palabras son solo un tipo de sonidos; por muy importante que sea su función en el cine narrativo, en la película prima la imagen, sobre todo cuando está coreografiada en el centro de la pantalla o en primeros planos. La imagen no es solo lo que recordamos -como demuestra constantemente el relato de Molina- sino lo que creemos. A lo largo de la novela, Marta es el objeto declarado y confeso del deseo de Valentín, mientras que la «Marta» del sueño es la figura de su repudio, el nombre con el que oculta su indecible amor por Molina. Pero la Marta que los espectadores ven sentada con Valentín en el bote de remos al final de la película es nuevamente el objeto de su deseo heterosexual. A pesar de que Braga está en todos los papeles femeninos -la propia Marta, Leni, la heroína de la película con la que se identifica Molina, e incluso la mujer araña, que es la imagen que Valentín tiene de Molina- ${ }^{24}$ la presencia en pantalla de Braga combinada con el nombre sonoro de Marta da a la película un final feliz banal que destruye el sutil equilibrio de la creación de Puig.

La función de la intertextualidad es específica tanto del medio como de la forma de expresión de cada texto. En I Walked with a Zombie las referencias intertextuales tanto a Jane Eyre como a White Zombie se realizan dentro de un medio de expresión, el cine, mientras que su forma de expresión puede decirse que transmite el horror de la historia. En Wide Sargasso Sea, la reformulación de Jane Eyre también se realiza dentro de un medio de expresión, el lenguaje, y la forma de expresión (el estilo literario) conlleva la perspectiva feminista y poscolonial. En El beso de la mujer araña, de Puig, la literatura y el cine se entrelazan completamente en un único texto cuyo medio es el lenguaje; su forma de expresión, que consiste en diálogos y monólogos internos, se compone de detalles visuales y señales espaciales como lo haría un guión a ser filmado de modo tal que el lector está al tanto de lo que ve y hace cada personaje. Es lo más parecido al cine que puede tener el lenguaje.

En la película de Babenco, el cine ni siquiera se acerca a lo que logra la novela. Lo que se pierde es el aspecto figurado o retórico del lenguaje de Puig, su poder para decir algo y significar otra cosa; esto no se traslada al medio del cine en la película. Ahora bien, el lenguaje del cine también está dotado de un poder retórico, de una figuralidad propia (metáforas cinematográficas, metonimias, sinécdoques, ironía, paradojas, etc.) y, en particular, del poder de desincronizar el sonido o de desvincularlo de la imagen. ${ }^{25}$ La transposición de una obra literaria a una película requeriría 
un proceso de creatividad intertextual. En ausencia de dicha creatividad, la película de Babenco, por mucho éxito comercial que tenga, sigue siendo una adaptación reducida de la novela de Puig.

\section{Referencias}

Blázquez, Gustavo (2014). «En carne viva. Algunas notas sobre zombis». Docta-Revista de Psicoanálisis, 10.

Brontë, Charlotte (1981) Jane Eyre. Bantam Classics. 1847.

De Lauretis, Teresa (2012). Panteridad: vivir en un cuerpo dañado. EU-topías. Revista de interculturalidad, comunicación y estudios europeos, 4, pp. 9-18.

De Lauretis, Teresa (2021). «I Walked with a Zombie: Colonialism and Intertextuality». EUtopías, Revista de interculturalidad, comunicación y estudios europeos. Volumen 21. Valencia: Universidad de Valencia -Departamento de Teoría de los Lenguajes y Ciencias de la Comunicación, 23-35.

Gilbert, Sandra and Gubar, Susan (1979). The Madwoman in the Attic: The Woman Writer and the Nineteenth-Century Literary Imagination. Yale University Press.

Puig, Manuel (1999). El beso de la mujer araña. Seix Barral. 1976

Rhys, Jean (1982). Wide Sargasso Sea. W. W. Norton Paperback. 1966.

Wekker, Gloria (2016). White Innocence: Paradoxes of Colonialism and Race. Duke University Press.

\section{Notas}

1. Una versión en inglés, bajo el título «I Walked with a Zombie: Colonialism and Intertextuality» (2021), puede leerse en EUtopías, Revista de interculturalidad, comunicación y estudios europeos, 21, pp. 23-35.

2. I Walked with a Zombie (Yo anduve con un zombi) (1943), producida por Val Lewton, dirigida por Jacques Tourneur, fotografía de J. Roy Hunt, música de Roy Webb, edición de Mark Robson, guión de Ardel Wray a partir de una historia original de Inez Wallace.

3. Como muchos de los que trabajan en Hollywood, Val Lewton era un inmigrante. Nacido en Yalta con el nombre de Vladimir Ivanovich Leventon (1904-1951) de una familia judía recién convertida, emigró a Nueva York siendo un niño de cinco años con su madre, Nina Leventon. Su hermana, Alla Nazimova, fue una famosa actriz de Broadway que posteriormente se convirtió en actriz y productora de cine en Hollywood; para los espectadores de cine, Nazimova es más conocida por su película muda Salomé (1923), basada en la obra de Oscar Wilde. Lewton creció, asistió a la universidad y comenzó su carrera de escritor en Nueva York, cambiando su nombre para adaptarlo a su profesión. A los 30 años, siendo un escritor de ficción pulp de alto nivel educativo pero con un éxito moderado, se trasladó a Hollywood para escribir una adaptación cinematográfica de Taras Bulba, de Gogol, para David O. Selznick, de RKO, donde también trabajó en películas como Anna Karenina, Lo que el viento se llevó y Rebeca.

4. Para dirigir I Walked with a Zombie y Cat People (La Mujer Pantera), quizás las dos películas más conocidas de las nueve, así como The Leopard Man, Lewton contrató a Jacques Tourneur, asignando la fotografía de Cat People a Nicholas Musuraca; contrató a Robert Wise, quien había sido editor principal de Citizen Kane y The Magnificent Ambersons de Welles para dirigir The Curse of the Cat People y The Body Snatcher; Mark Robson, quien había sido ayudante de edición de Wise en The Magnificent Ambersons, fue el editor de Cat People y I Walked with a Zombie (1942), y luego dirigió cuatro de las películas de Lewton: The 7th Victim (1943), Ghost Ship (1943), Isle of the Dead (1945), y Bedlam (1946); Simone Simon, el actor principal de Cat People, interpretó un papel muy diferente en la «secuela» The Curse of the Cat People (1944); Tom Conway, quien caracterizó al personaje de Rochester en I Walked with a Zombie, también interpretó al personaje del psiquiatra en Cat People y en The 7th Victim.

5. Dos ejemplos de I Walked with a Zombie: cuando la enfermera Betsy y Wesley están sentados a la mesa y oyen el sonido de los tambores procedentes del recinto de los 
nativos; o cuando Betsy comenta en el barco lo bonito que es todo, el canto de los marineros se oye de fondo como si estuviéramos en el lugar de Betsy. Esto sería esperable en una película de hoy en día, pero era bastante novedoso en 1943.

6. Por ejemplo, las persianas de las ventanas del dormitorio de Betsy y de otros lugares de la casa de los Holland son un detalle visual que se asocia posteriormente con el cine negro. Después de Cat People, Jacques Tourneur y Nicholas Musuraca volvieron a trabajar juntos como director y director de fotografía en la película de cine negro Out of the Past (1947), protagonizada por Robert Mitchum, Jane Greer y Kirk Douglas.

7. Por ejemplo, el sonido de los pies (de Carrefour) que se aproxima incluso antes de que su origen sea visible.

8. Val Lewton: The Man in the Shadows, escrito y dirigido por Kent Jones, producido y narrado por Martin Scorsese para Turner Classic Movies y Turner Entertainment Co. (2008).

9. «The Bagheeta», de Val Lewton, se publicó en el número de julio de 1930 de la revista Weird Tales.

10. Jane Eyre (1944) fue dirigida por Robert Stevenson para 2oth Century Fox.

11. Sir Lancelot es el nombre artístico del músico, compositor y cantante nacido en Trinidad que introdujo e hizo famoso en América el ritmo de África occidental conocido como calipso durante las décadas de 1940 y 1950. Posteriormente hizo muchas otras apariciones en el cine, de las cuales dos fueron en otras películas de Lewton. El calipso que compuso para I Walked with a Zombie se conoce también como «Shame and Scandal».

12. Gustavo Blázquez, «En carne viva. Algunas notas sobre zombis» (2014), DoctaRevista de Psicoanálisis (Córdoba, Argentina), 12(10), pág. 5.

13. Una oscura secuela ambientada en Camboya, Revolt of the Zombies (La rebelión de los zombis), supuestamente rodada en 1936.

14. Bela Lugosi interpretó el papel principal en el Drácula original, dirigido por Tod Browning para Universal Pictures en 1931

15. Un pequeño detalle atestigua la excelencia del guión y la actitud respetuosa de la película hacia la cultura nativa: Ti-Misery es el nombre utilizado por el cochero para el barco de esclavos, cuyo único vestigio es el San Sebastián de madera que era su mascarón de proa. Pero su recuerdo permanece en la gente de la isla que sigue añadiendo el prefijo «Ti» a sus nombres, como en el camarero Ti-Joseph e incluso en el niño recién nacido Ti-Victor.

16. Sobre la negación del pasado colonial del país en los Países Bajos contemporáneos, y por tanto la negación del racismo, véase White Innocence: Paradoxes of Colonialism and Race (La inocencia blanca: paradojas del colonialismo y la raza) de la antropóloga holandesa/surinamesa Gloria Wekker. (Duke University Press, 2016).

17. La palabra «criollo» se refiere a alguien nacido en la isla, ya sea de ascendencia europea o africana. Su padre era un médico galés y su madre una criolla blanca de ancestros escoceses. Rhys escribió sus tres primeras novelas mientras vivía en París y otros lugares de Europa durante la década de 1920: The Left Bank (1927), Quartet (1928) y After Leaving Mr Mackenzie (1930). Tras su regreso a Inglaterra, se publicaron dos más: Voyage in the Dark (1934) y Good Morning, Midnight (1939). Por último, tras un largo paréntesis, llegó Wide Sargasso Sea (1966).

18. The Madwoman in the Attic es el título de un libro sobre la novela victoriana escrito por las críticas literarias feministas Sandra Gilbert y Susan Gubar en 1979. Siguiendo el ejemplo de Virginia Woolf, demostraron que, en las novelas inglesas del siglo XIX, los personajes femeninos, restringidos a la esfera doméstica y apartados de la esfera social más amplia que pertenece a los hombres, son ángeles o monstruos. El personaje que llaman «la loca del ático» es el «monstruo», el anverso del que Woolf denominó «el ángel de la casa», es decir, la mujer que solo es esposa y madre. De hecho, «monstruo» es uno de los epítetos utilizados por Rochester para referirse a su esposa caribeña junto a «bestia salvaje, bruja, hiena vestida, maníaca, lunática y demonio», entre otros (Charlotte Brontë, Jane Eyre, Nueva York y Londres, Bantam Classics, 1981, pp. 279-294).

19. Jean Rhys, Wide Sargasso Sea. W. W. Norton Paperback, 1982 [1966], p. 17.

20. - ¿Has oído lo que cantaba esa chica? - dijo Antoinette. [Este intercambio está escrito con la voz de Rochester.]

- No siempre entiendo lo que dicen o cantan. O cualquier otra cosa.

- Era una canción sobre una cucaracha blanca. Esa soy yo. Así es como nos llaman a todos los que estábamos aquí antes de que su propia gente en África los vendiera a los traficantes de esclavos. Y he oído a las inglesas llamarnos negros blancos (Rhys, 1982:102).

21. Solo un ejemplo: el relato de Molina de la película «sobre una mujer zombi» (que en el original tiene un título, La vuelta de la mujer zombi [141]) comienza con «una 
chica de Nueva York toma el vapor hacia una isla del Caribe donde la espera el novio para casarse» (163-164).). Resulta que el prometido había estado casado con la mujer zombi y, tras intrincados giros de la trama, es asesinado por la misma mujer zombi, quien más tarde muere en una gran hoguera. La película contada termina con la chica abandonando la isla en un barco y aferrándose al capitán, «por suerte, es el mismo capitán buen mocísimo que salió al principio», mientras «la música de amor de todo ese pueblo le está dando la despedida para siempre y le augura un futuro lleno de felicidad...» (216)

22. Por ejemplo, de la película favorita de Molina sobre una cantante francesa que se enamora de un oficial alemán en el París ocupado por los nazis, Valentín comenta con severidad (y acierto) que «es basura nazi» (56). Esta película fue enteramente inventada por Puig, que también fue autor de varios guiones, además de obras de teatro y novelas como La traición de Rita Hayworth (1968), Boquitas pintadas (1969) y Cae la noche tropical (1988).

23. «El amor que no se atreve a decir su nombre» es una frase de un poema de Lord Alfred Douglas, amante de Oscar Wilde. Citada en el juicio de Wilde (1895) y luego provocando su condena, la frase se ha convertido en un sinónimo de amor homosexual.

24. - Es cierto, no sos la mujer pantera.

- Es muy triste ser mujer pantera, nadie la puede besar. Ni nada.

- Vos sos la mujer araña que atrapa a los hombres en su tela.

- ¡Qué lindo! Eso sí me gusta.» (265)

La referencia a la mujer pantera es del relato de Molina en la primera película, Cat People (LaMujer Pantera).

25. Un ejemplo de intertextualidad creativa de la literatura al cine es Cat People, la primera de las nueve películas de terror producidas por Val Lewton, seguida ese mismo año por I Walked with a Zombie. Cat People (1942) se desarrolló a partir de «The Bagheeta», el relato corto de Val Lewton (véase n. 8). La creatividad intertextual de la película es más notable en la desincronización de sonidos e imágenes. Sobre Cat People, véase T. de Lauretis, «Panteridad: vivir en un cuerpo dañado», EU-topías, Vol. 4 (2012), 9-18. 